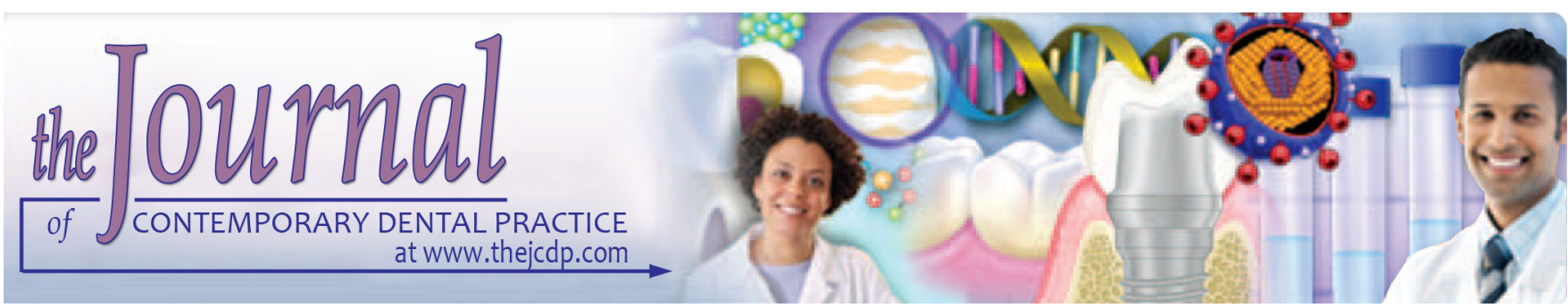

\title{
Behaviors and Management of the Dental Problems by the Residents of Madinah, Saudi Arabia
}

\author{
${ }^{1}$ Mohammad Sami Ahmad, ${ }^{2}$ Khalid Mohammad Al-Harbi
}

\begin{abstract}
Introduction: Dental problems are commonly encountered in our lives. Some of the common problems are toothache, bleeding gums and halitosis.
\end{abstract}

Objectives: How the dental problems were handled, and reasons of not seeking dental treatment by the patients.

Materials and methods: This was an observational analytical cross-sectional study on adult's age above 14 years from Madinah

Results: A total of 400 adults were included; 208 (52\%) were males and 192 (48\%) were females. Resident encountered toothache surprisingly only $49 \%$ sought dental treatment, while $(41 \%)$ settled for taking medications. Among bleeding gum patients most of them (45\%) went to the dentist, while (41\%) settled for using the home care. And dealing with halitosis only $(17 \%)$ went to the dentist. The most common reasons for not seeking dental treatment were fear and long appointments. And mostly they had fear because of dental drill and dental needle.

Conclusion: The most common problems for seeking treatment were toothache followed by bleeding gums and the least was halitosis. Number of people who sought treatment was still a low number. The most common reason that stopped patients from going to the dentist was fear and long appointments. There should be increase of dental clinics and patients should be given dental education.

Keywords: Bleeding gum, Dental drill, Fear, Halitosis, Toothache.

How to cite this article: Ahmad MS, Al-Harbi KM. Behaviors and Management of the Dental Problems by the Residents of Madinah, Saudi Arabia. J Contemp Dent Pract 2015;16(10): 783-787.

\footnotetext{
${ }^{1}$ Department of Preventive Dental Science, College of Dentistry Taibah University, Madinah, Saudi Arabia

${ }^{2}$ Intern, College of Dentistry, Taibah University, Madinah, Saudi Arabia

Corresponding Author: Mohammad Sami Ahmad, Associate Professor, Department of Preventive Dental Science, College of Dentistry, Taibah University, Madinah, Saudi Arabia, Phone: 00966531640794, e-mail: msamiahmad@hotmail.com
}

\section{Source of support: Nil}

\section{Conflict of interest: None}

\section{INTRODUCTION}

Pain is a common disabling condition with a high impact on health and health services in the community globally. ${ }^{1}$ We encounter dental problems very often in our lives. It is important to get the proper treatment as soon as the dental problem arises to avoid further complications. ${ }^{2}$ The way people handle dental problems can defers from one person to another due to many factors like work, fear, access to dental care and cost of treatment. ${ }^{3}$ Most of the common dental problems patient's reports to dentists in the form of toothache are due to dental caries, gingivitis or periodontitis. The other problem is halitosis which gives the patients psychosocial trauma. ${ }^{4}$

Toothache may be caused due to dental conditions, or nondental conditions. There are many possible nondental causes, but the majority of toothache is of dental origin. ${ }^{2}$ One of the most common cause of orofacial pain is toothache ${ }^{5}$ and, when it is severe, considered as dental emergency. Sleeping, eating, and other daily activities are disturbed due to significant impact of toothache. Toothache is one of the most common reasons for dental emergency. ${ }^{6}$ It may occur at any age, gender and in any geographical region. Pulpitis is the most common reason for toothache. Irreversible pulpitis is the most common reason that people need emergency dental treatment. Dental caries with pulpitis is the most common reason for toothache among the populations. ${ }^{4}$

Other dental problem is gingivitis, which is nondestructive. ${ }^{7}$ The most common form of gingivitis is actually in response to bacterial biofilms called plaque. It is adherent to tooth surfaces and termed plaque-induced gingivitis. Gingivitis could be reversible if oral hygiene is maintained. If gingivitis is not treated it may progress 
in to periodontitis. Periodontitis leads to inflammation and later results tissue destruction and alveolar bone resorption and ultimately lead to tooth loss. ${ }^{8}$ In some person or in some oral site gingivitis never progresses to periodontitis ${ }^{9}$ but some data show that periodontitis is always preceded by gingivitis. ${ }^{10}$ Symptoms that patients complain of bleeding when brushing or flossing, swollen, tender gum and halitosis.

Halitosis, colloquially called bad breath, feter oris, or fege bosta is a symptom in which a noticeably unpleasant odor is present in the patient breath? Halitosis is thought to be the third most common reason for people need dental care, followed by tooth decay and gum disease. ${ }^{11}$ About $20 \%$ of the population have reported to suffer from halitosis of some degree. Many people think that they have halitosis, are not serious about problem. Only significant percentage of people feels that they have halitosis ${ }^{12}$ and when professionally examined it is not. Some have genuine halitosis but on examination it is found that the odor is caused due to bacteria present in the plaque deposited on cervical region of tooth and on the back of the tongue. The remaining odor is accounted for many different conditions, such as disorder in nasal cavity, sinuses, throat, lungs, esophagus and stomach. Sometime halitosis might be due to some serious medical condition, such as liver failure but in majority of cases the cause is minor and can be decreased by oral hygiene adjustment by regular practice of brushing teeth and massaging gum, using dental floss and scraping the back of the tongue. Occasionally, if the origin of the odor is not from the mouth, halitosis can be difficult to diagnose and manage successfully. Halitosis is one of the factors for anxiety and depression because it causes psychosocial trauma.

\section{MATERIALS AND METHODS}

This was an observational analytical cross-sectional study, which was carried out on residents of Madinah aged 14 years and above. Children under 14 years were excluded from this study, because of their dental decisions are mostly taken by their parents. The study was conducted between April and May 2015 by means of an online questionnaire. The questionnaire consisted of three parts of a total of 10 multiple choice questions. The first part of the questionnaire dealt with basic information, gender, age and education level. The second part asked to residents how they managed their dental problems like toothache, bleeding gums and halitosis. Meanwhile the third and last part was concerned on reasons keeping them away from consulting dentists for dental treatment. Epi Info software was used to calculate sample size. Based on a population size of Madinah: 1,180,770 based on the latest population count $(2010)^{13}$ for power of the study of $95 \%$ we need 385 participants. We decided to set sample size to 400 . The sample was a convenient one. The reliability of the survey was tested by the means of Test-Retest reliability and it got an acceptable score.

The data were coded and keyed into the Statistical Package for the Social Sciences software version 19 (SPSS Inc, Chicago, IL) used in Windows 7. Descriptive analysis was used. The Research Ethics Committee of the College of Dentistry, Taibah University, approved this study. The consent was waivered because all of the collected data will be confidential and anonymous.

\section{RESULTS}

Total 400 residents of Madinah having dental problem were included in this study. Among them, males were $52 \%(n=208)$ and female were $48 \%(n=192)($ Graph 1$)$.

Almost a half of the participants $172(43 \%)$ were aged 14-24, followed by 25 to 34 (23\%) and least 9 (2.3\%) age groups was from 55 and above (Graph 2).

Resident's encountered toothache, about half 196 (49\%) of them sought treatment, while 164 (41\%) of them settled for taking home remedy like pain killers. Only 40 $(10 \%)$ did nothing to solve the problem (Graph 3).

There was not any difference between sex and way they manage their toothache problem, 94 (49\%) female contacted dentists to solve their problem. Same percentage 103 (49\%) male also contacted the dentist to solve their problem (Table 1).

Among the age group of 14 to 24 years, who visited the dentists to solve their problem was $41 \%$ while $89 \%$ resident belong to age group of 55 and above visited the dentist. In younger group mostly avoiding to go to the dentist where as senior group preferred to go to the dentist (Table 2).

When the residents had bleeding gums, 180 (45\%) of them went to the dentist while 164 (41\%) used home care

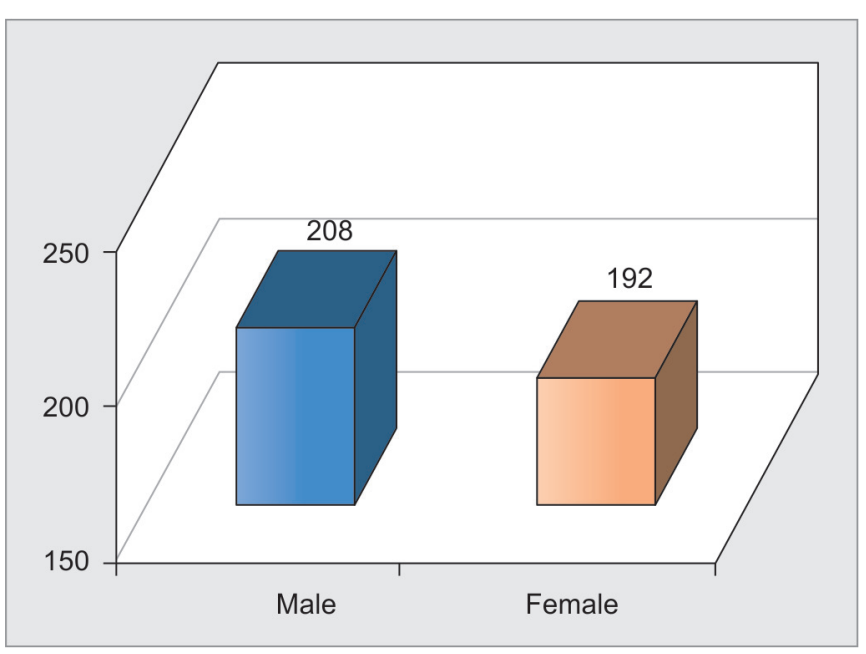

Graph 1: Participation of people by sex 
Table 1: Management of toothache by gender

\begin{tabular}{lllll}
\hline & \multicolumn{3}{c}{ Toothache } & \\
\cline { 2 - 4 } & $\begin{array}{l}\text { Contacted } \\
\text { dentist }\end{array}$ & $\begin{array}{l}\text { Used pain } \\
\text { killers }\end{array}$ & $\begin{array}{l}\text { Did not do } \\
\text { anything }\end{array}$ & Total \\
\hline Female & $94(49 \%)$ & $85(44 \%)$ & $13(7 \%)$ & $192(100 \%)$ \\
Male & $103(49 \%)$ & $79(38 \%)$ & $26(13 \%)$ & $208(100 \%)$ \\
\hline
\end{tabular}

$p=0.038$

Table 2: Management of toothache by age

\begin{tabular}{lllll}
\hline & \multicolumn{3}{c}{ Toothache } & \\
\cline { 2 - 4 } & $\begin{array}{l}\text { Contacted } \\
\text { dentist }\end{array}$ & $\begin{array}{l}\text { Used pain } \\
\text { killers }\end{array}$ & $\begin{array}{l}\text { Did not do } \\
\text { anything }\end{array}$ & Total \\
\hline $\begin{array}{l}14-24 \text { Age } \\
\text { (years) }\end{array}$ & $70(41 \%)$ & $72(42 \%)$ & $30(17 \%)$ & $172(100 \%)$ \\
$\begin{array}{l}25-34 \text { Age } \\
\text { (years) }\end{array}$ & $48(52 \%)$ & $38(41 \%)$ & $6(7 \%)$ & $92(100 \%)$ \\
$\begin{array}{l}35-44 \text { Age } \\
\text { (years) }\end{array}$ & $44(55 \%)$ & $34(43 \%)$ & $2(2 \%)$ & $80(100 \%)$ \\
$\begin{array}{l}45-54 \text { Age } \\
\text { (years) }\end{array}$ & $27(58 \%)$ & $19(40 \%)$ & $1(2 \%)$ & $47(100 \%)$ \\
55 and above & $8(89 \%)$ & $1(11 \%)$ & $0(0 \%)$ & $9(100 \%)$ \\
\hline
\end{tabular}

$p=0.000$

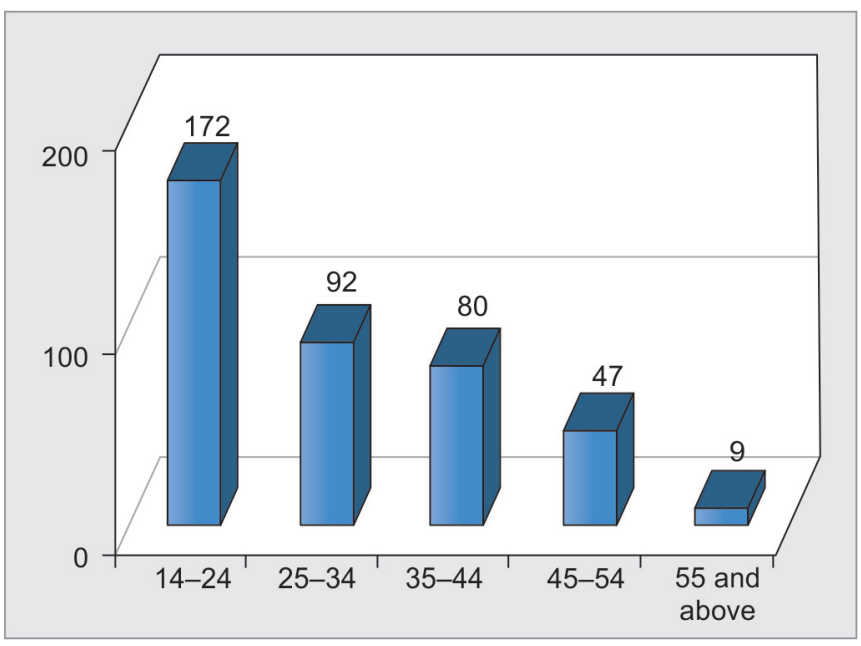

Graph 2: Participation in the study age wise

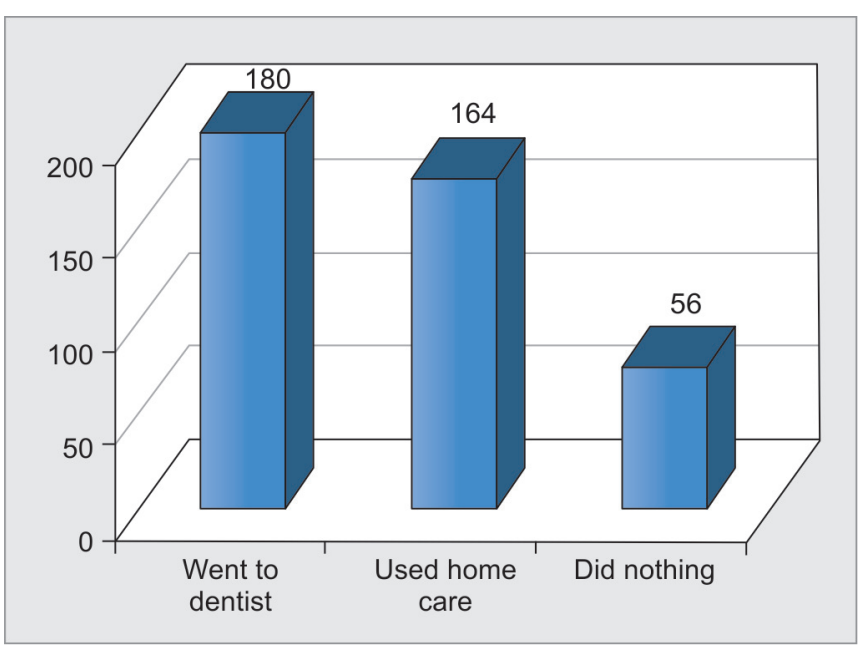

Graph 4: Bleeding gum management like toothbrush, mouthwash, chewing gum and only 56 (14\%) did nothing (Graph 4).

Related to halitosis $68(17 \%)$ visited the dentist while the $322(80.5 \%)$ did home care like using the toothbrush, mouthwash, chewing gum and miswak. Only $10(2.5 \%)$ residents did nothing to stop the halitosis (Graph 5).

The four most common reasons for not seeking dental treatment were fear and long appointment both were mostly equal 108 (27\%) and 106 (26.5\%) followed by increased cost of treatment $86(21.5 \%)$. Only few residents told about not proper access of clinics (Graph 6).

Maximum number of residents had fear from dental drill and dental needle that was 120 (30\%) and 112 (28\%) followed by increase of pain and bad previous experience (Graph 7).

\section{DISCUSSION}

Most common dental diseases are dental caries, gingivitis and periodontitis. These diseases lead to toothache and patients need to overcome from these problem. In

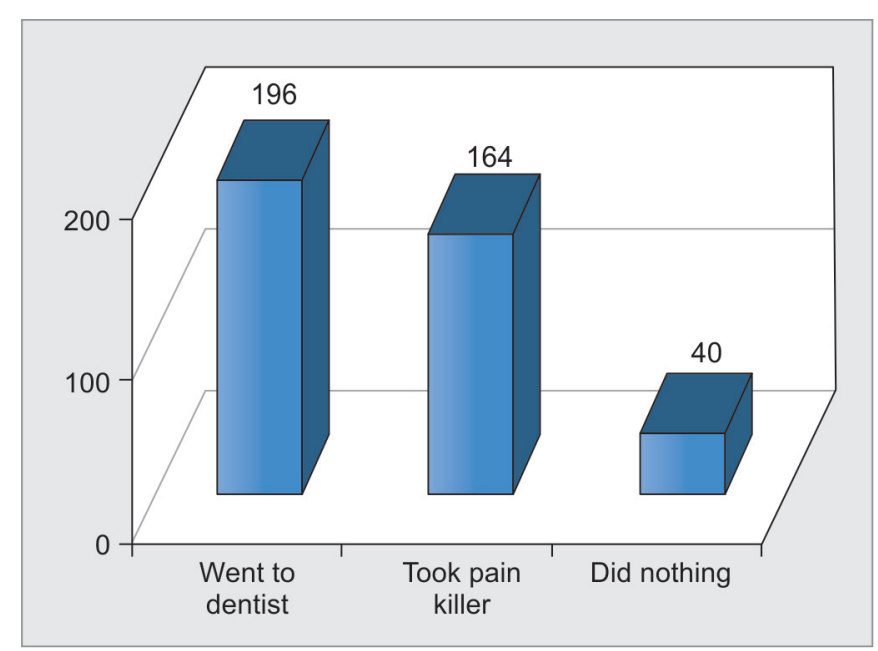

Graph 3: Toothache management

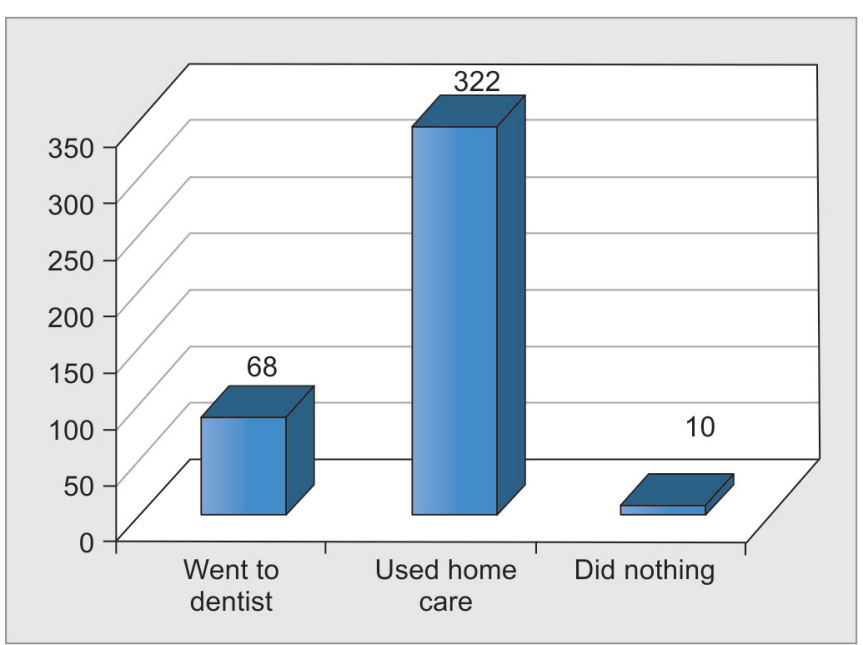

Graph 5: Halitosis management 


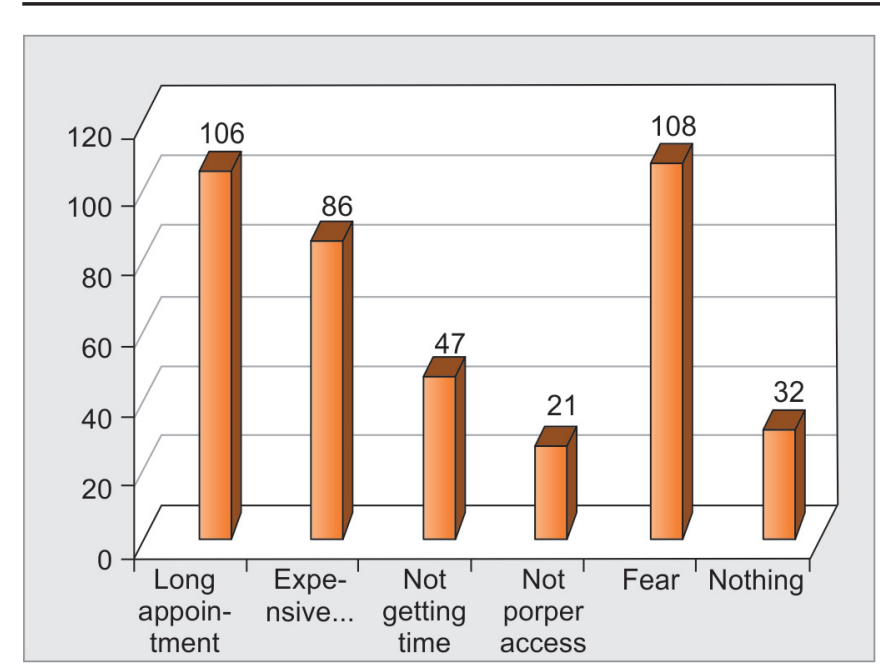

Graph 6: Reason for not seeking dental treatment

developed countries, people are more conscious about health so, they are in need of preventive treatment while in developing countries patients are not very serious about the diseases unless it becomes life threatening. Only they visit the clinics when they are having pain or discomfort. May be the reasons lack of knowledge about the disease, not proper access to the clinic or fear. Halitosis is the other problems, which give more stress to the patient due to psychosocial trauma. In this study, we tried to find out the patients suffering from toothache and halitosis, among them how many visit the dentist to get rid of the problem. In this study, $52 \%$ were male and $48 \%$ were female. Out of 400 participants, $50 \%$ were from 19 to 24 years age group. Male and female both replied mostly about equal in number and among them highest numbers of respondents were from age group 19 to 24 years of age. Dental diseases are not only gives pain or discomfort but it also affects the aesthetic of the patients. Younger groups are more conscious about their oral health as compare to elders one. Among the patients having toothache, only about half $49 \%$ visited the dentists and $41 \%$ relied on home remedy. In Nigerian study, $56 \%$ of the people used to take medication like painkiller, which is more close to, our study. ${ }^{1}$ It is very surprisingly, especially in Saudi Arabia where they have better facilities for healthcare. Most of the primary health centers are equipped with dental clinic and provide dental care. Majority of patients describe for not visiting the dentist is fear about 27\% (Graph 6) and fear mostly due to dental drill and dental needle while surprisingly $92(23 \%)$ said that they are worried that visiting the dentist will increase the pain and 71 $(18 \%)$ describes bad experience in previous visit to the dental clinic (Graph 7). Lul Lu et al 2015 described reason not to visit dentist was cost, approach to dental clinics. ${ }^{14}$ Young adults are more often afraid of dental treatment in compare of middle-aged people ${ }^{4}$ and anxiety is more

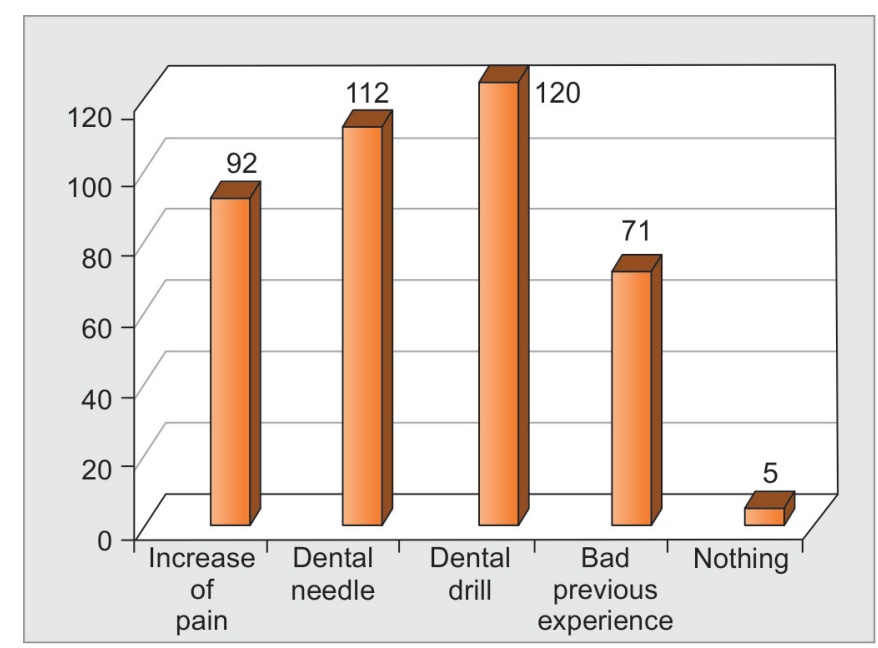

Graph 7: Reason for fear that kept away from dentist

common among women, the ratio women to men may be 2:1. ${ }^{15}$ This may be due to different perception of feeling between men and women and may be different cultural expectations to men and women rather than actual difference. ${ }^{16}$ Dental fear is also affected by the patient's perception of treatment situation. Fearful patients visit the dentist less regularly and come only when in severe pain or dysfunction. Armfield et al suggested that the dentist could easily reduce these predictors of dental fear if he/she is attentive to this and adjust the treatment after the patient's need. ${ }^{17}$ If patient could be involved in the treatment and allowed to give signal by raising hand, then the dentist should stop the treatment and not start until the patient is ready. During the first visit, a patient should be given time to adjust himself and ready to get the treatment. If pain occurred during the treatment, the patient should be informed about the pain why it occurred and how to avoid? This way patient would develop the confidence over dentists and it would be helpful in reducing dental fear. ${ }^{18}$ Reason for less number of residents visited dentist might be poor health education they did not consider halitosis or bleeding gum as dental problem.

\section{CONCLUSION}

Most common problem for going to the dentist was toothache followed by bleeding gums and the least was halitosis. For toothache and bleeding gums half of the people went to the dentist to solve their dental problems but it was still a low number. Many residents were using home care like toothbrush and mouthwash to deal with the problems. There is no significant difference in how the two genders on how they solve their dental problems. The most common reason that stopped patients from going to the dentist was fear followed by long appointments and increased cost. 


\section{REFERENCES}

1. Azodo CC, Ololo O. Toothache among dental patients attending a Nigerian secondary health care setting. Stomatologija Baltic Dent Maxilofac J 2013;15(4):135-140.

2. Hargreaves KM, Cohen S, Berman LH. Cohen's pathways of the pulp. 10th ed. St Louis, Mo: Mosby Elsevier; 2011.

3. Pattussi MP, Peres KG, Boing AF, Peres MA, da Costa JS. Self related oral health and associated factors in Brazilian elders. Community Dent Oral Epidemiol 2010;38:348-359.

4. Kakoei S, Parirokh M, Nakhaee N, Jamshidshirazi F, Rad M, Kakooei S. Prevalence of toothache and associated factors: a population based study in Southeast Iran. Iran Endod J 2013; 8(3):123-128.

5. Scully C. Oral and maxillofacial medicine: the basis of diagnosis and treatment. 3rd ed. Edinburgh: Churchill Livingstone/Elsevier; 2013.

6. Calderon dSP, Peixoto RF, Gomes VM, da Mota Correa AS, deAlencar EN, et al. Concordance among different pain scales in patients with dental pain. J Orofac Pain 2012;26:126-131.

7. The American Academy of Periodontology. Proceedings of the World Workshop in Clinical Periodontics. Chicago: The Am Acad Periodontol 1989:I/23-I/24.

8. Idrees MM, Azzeghaiby SN, Hammad MM, Kujan OB. Prevalence and severity of plaque induced gingivitis in a Saudi adult population. Saudi Med J 2014;35(11):1373-1377.

9. Ammons WF, Schectman LR, Page RC. Host tissue response in chronic periodontal disease. The normal periodontium and clinical manifestations of dental and periodontal disease in the marmoset. J Periodont Res 1972;7(2):131-143.

10. Page RC, Schroeder HE. Pathogenesis of inflammatory periodontal disease. A summary of current work. Laboratory investigation. J Tech Methods Path 1976;34(3):235-249.

11. Loesche WJ, Kazor C. Microbiology and treatment of halitosis. Periodontol 2000 2002;28:256-279.

12. Harvey-Woodworth CN. Dimethylsulphidemia: the significance of dimethyl sulphide in extraoral, blood borne halitosis. BDJ 2013;214(7):E20.

13. Population. Statistical Yearbook 47 (2011). Central Department of Statistics and Information. Retrieved 2011;15 November 2013.

14. Lu L, Zhang Y, Wu W, Cheng R. Characteristics of dental care seeking behaviour and related sociodemographic factors in a middle aged and elderly in northeast China. BMC Oral Health 2015;15:66.

15. Haukebø K, Skaret E, Öst L-G, Raadal M, Berg E, Sundberg H, et al. One vs five session treatment of dental phobia: a randomized controlled study. J Behav Therapy Experi Psych 2008;39(3):381-390.

16. Locker D, Thomson WM, Poulton R. Psychological disorder, conditioning experiences, and the onset of dental anxiety in early adulthood. J Dent Res 2001;80(6):1588-1592.

17. Armfield JM. Towards a better understanding of dental anxiety and fear: cognitions vs experiences. Eur J Oral Sci 2010;118(3):259-264.

18. Vassend O. Anxiety, pain and discomfort associated with dental treatment. Behav Res Therapy 1993;31(7):659-666. 